\section{DNA damage control}

\author{
By Kai-Jye Lou, Staff Writer
}

Researchers at the University of Chicago have identified a compound called RS- 1 that boosts the activity of the DNA repair protein RAD51, which is normally associated with tumorigenesis and resistance to chemotherapy and also plays a key role in preventing DNA damage in healthy cells. ${ }^{1}$ Although RS-1 protects healthy cells from DNA damage caused by cisplatin in vitro, a therapeutic development strategy will have to address the molecule's potential to increase both mutagenesis in healthy cells and drug resistance in cancer cells.

RAD51 encodes a strand-exchange protein that directly interacts with DNA. The RAD51 protein plays a key role in homologous recombination, which is required for certain types of DNA repair.

In a paper in the Proceedings of the National Academy of Sciences, a research group led by Philip Connell identified RS-1 using in vitro screens and showed that the molecule increased the function of RAD51 by stabilizing its interaction with DNA. In cultured, noncancerous human fibroblasts treated with cisplatin, RS-1 produced dose-dependent increases in cell survival compared with what was seen in cells not supplemented with RS-1.

Connell is an assistant professor in the Department of Radiation and Cellular Oncology at the University of Chicago. He said identifying a compound that enhanced homologous recombination was essential because "repair of certain types of DNA damage seem to require this pathway, based on hypersensitivity seen in cells with impaired recombination."

For example, he noted that mitomycin $\mathrm{C}$ and platinum-based chemotherapeutics can cause DNA interstrand cross-links, which seem to require homologous recombination for repair.

\section{Protective, but selective}

Based on his group's results, Connell thinks RS-1 and its derivatives are potential candidates for protecting healthy tissue against the DNAdamaging effects of chemotherapy and radiation. However, because of the central role of RAD51 in homologous recombination, previous studies suggest that two potential side effects of the molecule will have to be carefully assessed: increased mutagenesis in healthy cells and increased drug resistance in cancer cells. ${ }^{2,3}$

For example, Hannah Klein, a professor of biochemistry, medicine and pathology at the New York University Langone Medical Center, cautioned that upregulating RAD51 expression can promote abnormal homologous recombination and increase the risk of cancer-causing genetic rearrangements in healthy cells.

One solution, said Connell, might be to dose RS-1 for short periods of time. Doing so could temporarily protect healthy cells from DNA damage while minimizing the risk of aberrant genetic rearrangements. "If one were to increase homologous recombination for a long period of time, there is the risk for increased mutagenesis," he acknowledged. "But one could imagine using it for a shorter period of time like prior to chemotherapy, such that the benefits of normal tissue protection may outweigh this risk."

Debiopharm S.A.'s Maximilien Murone agreed. "In theory, RS1 might potentially be used to transiently elevate cellular resistance to DNA damage prior to treatment with DNA-damaging drugs," he said.

Murone is associate director of an office established by Debiopharm and The Swiss Federal Institute of Technology, Lausanne to manage joint projects. The company has developed Eloxatin oxaliplatin, a platinum atom complexed with oxalate and diaminocyclohexane that is marketed in the U.S. and Europe by sanofi-aventis Group to treat colorectal cancer.

Inversely, both Murone and Frédéric Lévy, scientific evaluator in oncology at Debiopharm, suggested that, in the case of tumors with high levels of RAD51, it would be more appropriate to inhibit RAD51 to sensitize cancer cells to chemo- or radiotherapy.

One such compound is MP-470 from SuperGen Inc., a multitargeted tyrosine kinase inhibitor that suppresses c-Met, c-Ret and the RAD51 protein. It is in Phase I testing to treat solid tumors. Preclinical data showed that MP-470 suppresses DNA double-strand break repair and sensitizes cancer cells to radiation and platinum-based chemotherapeutics.

Andy Tomlinson, senior director of biochemistry and molecular biology at Antigenics Inc., and NYU's Klein both argued that it will be important to develop strategies to target the delivery of RS-1 to healthy tissues.

Antigenics is running Phase I studies of aroplatin to treat solid tumors and B cell lymphoma (BCL). An earlier formulation of the third-generation liposomal platinum analog had completed a Phase II trial in colorectal cancer.

\section{Resistance movement}

Dosing issues aside, Kenneth Tew, chairman of the Department of Cell and Molecular Pharmacology and Experimental Therapeutics at the Medical University of South Carolina, and Tomlinson both were concerned that systemic use of RS-1 to increase RAD51 expression might render tumors resistant to chemotherapeutics. As a result, they wanted to know whether the protective effects of RS-1 were specific to healthy tissue. 


\section{TARGETS \& MECHANISMS}

Connell said his team has tested RS-1 in multiple tumor cell lines that overexpress RAD51 and has not detected tumor-protective effects. Going forward, he said the group will be collaborating with medicinal chemists to optimize and improve the potency of RS-1.

Connell wants to move into animal models to see if RS-1 can lower injury to normal tissues following treatment with radiation or DNAdamaging drugs like cisplatin.

The University of Chicago has a pending patent covering the use of RS-1 and its derivatives in undisclosed indications. The compounds are available for licensing through the Office of Technology \& Intellectual Property at the university.

Lou, K.-J. SciBX 1(38); doi:10.1038/scibx.2008.916

Published online Oct. 23, 2008

\section{REFERENCES}

1. Jayathilaka, K. et al. Proc. Natl. Acad. Sci. USA; published online Sept. 29, 2008; doi:10.1073/pnas.0808046105

Contact: Philip P. Connell, University of Chicago, Chicago, III. e-mail: pconnell@radonc.uchicago.edu

2. Klein, H.L. DNA Repair (Amst.) 7, 686-693 (2008)

3. Slipianek, A. et al. Mol. Cell 8, 795-806 (2001)

COMPANIES AND INSTITUTIONS MENTIONED Antigenics Inc. (NASDAQ:AGEN), New York, N.Y. Debiopharm S.A., Lausanne, Switzerland Medical University of South Carolina, Charleston, S.C. New York University Langone Medical Center, New York, N.Y. sanofi-aventis Group (Euronext:SAN; NYSE:SNY), Paris, France SuperGen Inc. (NASDAQ:SUPG), Dublin, Calif.

The Swiss Federal Institute of Technology, Lausanne, Switzerland University of Chicago, Chicago, III. 